\title{
Chest wall hydatidosis as the unique location of the disease: Case report and review of the literature
}

\author{
Christophoros N Foroulis MD PhD, Constantinos Avgoustou MD, \\ Marios Konstantinou MD, Achilleas G Lioulias MD PhD
}

\begin{abstract}
CN Foroulis, C Avgoustou, M Konstantinou, AG Lioulias. Chest wall hydatidosis as the unique location of the disease: Case report and review of the literature. Can J Infect Dis 2003;14(3):167-169.

The chest wall is a rare location of secondary hydatidosis, but secondary hydatidosis may occur from the rupture of a lung cyst, from a liver cyst invading the diaphragm into the pleural cavity, following previous thoracic surgery for hydatidosis, or by hematogenous spread. This report describes a case of chest wall hydatidosis, which was the primary disease site in the patient, who had no previous history or current disease (hydatidosis) at other sites. The cyst invaded and partially destroyed the 9 th and 10th ribs and the 10th thoracic vertebra, and protruded outside the pleural cavity through the 9th intercostal space. Preoperative albendazole administration for 10 days, surgical resection of the disease through a posterolateral thoracotomy incision, and postoperative albendazole treatment resulted in a cure with no evidence of local recurrence or disease at other sites in four years of follow-up.
\end{abstract}

Key Words: Chest wall echinococcosis; Echinococcosis; Hydatidosis; Pseudotumours of the chest wall

\section{Paroi de la cage thoracique, seul foyer d'hydatidose: Exposé de cas et examen de la documentation.}

$\mathrm{H}$ uman echinococcosis (hydatidosis) is a parasitic disease that was first identified by Hippocrates. The disease is endemic in many parts of the world $(1,2)$. The majority of cases - approximately $90 \%$ - are caused by the parasite Echinococcus granulosus $(1,3)$. Less common species of Echinococcus that cause human disease are: Echinococcus multilocularis or Echinococcus sibericensis caused by the foxes and rodents of Siberia, Alaska and Central Europe, which cause alveolar hydatid disease of the liver, Echinococcus vogeli, in South America and Echinococcus oligarthrus in South and Central America (1-5). In Greece, the disease is endemic with an annual incidence of hydatidosis, caused exclusively by $E$ granulosus, of 10 cases per 100,000 inhabitants (unpublished data).

In $85 \%$ of the cases $E$ granulosus affects either the liver, lungs, or both, although any organ can be affected (5). Hydatidosis of the chest wall as the primary manifestation of the disease is rare $(1,3,6)$. We report a case of chest wall hydatidosis and discuss the differential diagnosis of chest wall tumors and treatment.

\section{CASE DESCRIPTION}

A 28-year-old urban, vegetarian woman who worked as a nurse was admitted for evaluation of a smooth, palpable cystic paravertebral mass of the right hemithorax. A physical examination revealed a smooth cystic mass protruding through the 9th intercostal space. A chest radiography and a Computerized Tomography (CT) scan identified a multivesicular cystic mass that had invaded and partially destroyed the 9 th and 10th ribs, and the 10th thoracic vertebra (Figure $1)$. The density of the mass was close to that of water, consistent with a hydatid cyst (Figure 2). An ELISA for antiechinococcal antibodies was positive. A CT scan of the abdomen was negative for cysts at other locations.

The patient received 10 days of albendazole, $800 \mathrm{mg}$ daily, then underwent surgery. A right lower posterolateral thoracotomy at the 7 th intercostal space was performed. The thoracotomy incision and the pleural cavity were separated from the operating field using $15 \%$ saline-soaked gauze pads to avoid contamination with the cyst contents, should rupture occur. The laminated membrane was easily dissected away

Athens Chest Diseases Hospital "Sotiria", 2nd Department of General Thoracic Surgery, Athens, Greece

Correspondence and reprints: Dr Christophoros N Foroulis, 35 Ioustinianou Street, Larissa, Greece 41223. Telephone +302410-287466 or +306944-910343, fax +302410-611097, e-mail foroulis@internet.gr

Received for publication August 19, 2002. Accepted February 5, 2003 




Figure 1) A hydadit cyst invading and destroying the 9th thoracic vertebra and the 9th rib. Multiple daughter cysts are contained within the cyst

from the parietal pleura. After a partial needle aspiration of the cyst fluid, a $15 \%$ saline solution was injected to sterilize the contents. A sharp dissection was necessary to separate the cyst membrane from the adjacent vertebrae, ribs, and diaphragm because of extensive pericystic fibrosis and the loss of the cleavage plan. A rupture of the cyst occurred during the dissection of the cystic membrane from the invaded and partially destroyed 10th vertebra and 9th and 10th ribs. The cyst contained many daughter cysts (Figure 1). Some remnants of the cystic membrane in the affected ribs and vertebra were destroyed using electrodiathermy. The pleural cavity was sterilized with a $15 \%$ saline solution and drained with two chest tubes. A microscopic examination of the cyst membrane and protoscolices in the cyst fluid showed the presence of E granulosa.

The patient had an uneventful postoperative course and was discharged after seven days. Six cycles of albendazole were administrated postoperatively: $400 \mathrm{mg}$ twice daily for 28 consecutive days, followed by 14 days of treatment discontinuation before the next 28-day cycle. A CT scan of the chest and abdomen at four years follow-up showed no evidence of new cysts or local recurrence. Echinococcal antibodies remained negative.

\section{DISCUSSION}

The chest wall is an uncommon location of hydatidosis. It may be involved through spontaneous or operative rupture of a pulmonary or liver (with diaphragm invasion) cyst into the pleural space (3). Hematogenic spread may also lead to chest wall involvement. Rarely, embryos with a diameter of less than $0.3 \mathrm{~mm}$ may escape from the liver and lung capillaries to involve any organ via the systemic circulation.

From 1991 to 2000 the frequency of chest wall hydatidosis in our thoracic surgery practice was $7.69 \%$ (four of 52 cases). There were three with pleural locations, and one with a soft tissue location. Three of these four cases were cases of secondary hydatidosis in patients with multiorgan involvement. The fourth case, reported here, was a patient with a pleural site as the only location of the disease.

The incidence of chest wall involvement was $0.09 \%$ to $3.4 \%$ in two large series (6500 to 8000 subjects) of reported cases $(2,7)$. A pleural location is the most common location of chest wall hydatidosis, while a costal location has been rarely reported

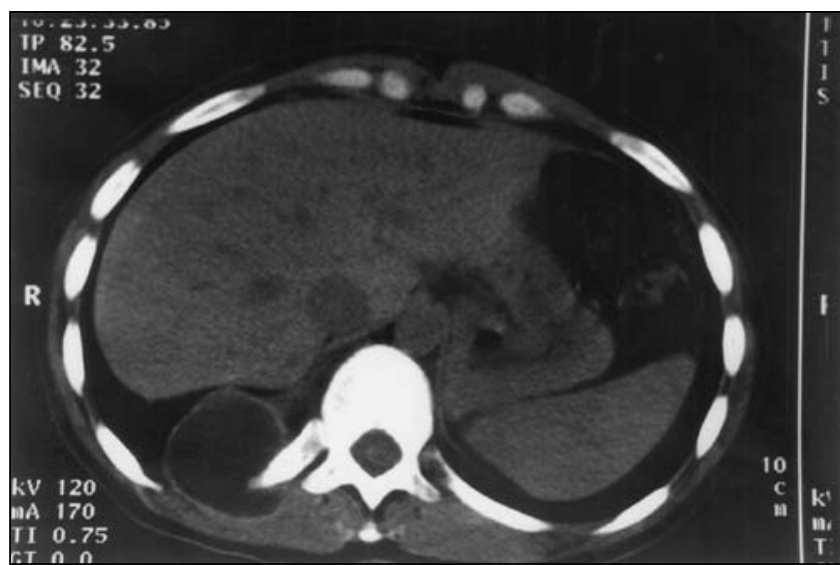

Figure 2) A hydadit cyst at a lower level, protruding through the 10th intercostal space

(2). Oguzkaya et al (2) described three cases of chest wall hydatidosis, for two of whom the chest wall was the only site of the disease. Two of the six cases of chest wall hydatidosis described by Özdemir et al (3) were the only sites of the disease.

There are three reports of cases of chest wall hydatid cysts mimicking chest wall tumours (8-10). The enlargement of the hydatid cyst results in ischemia and destruction of the thoracic bones. The invasion and destruction of bones and the protrusion of the cyst through the intercostal space were both observed in our case. However, the density of the cystic mass being close to that of water on the CT scan should raise the suspicion of hydatidosis even in nonendemic areas. To prevent dissemination, fine needle aspiration of the mass should be avoided unless other diagnostic methods have failed (6).

The presence of positive echinococcal serology supports the diagnosis, in combination with the imaging findings (11). Echinococcal serology is also useful for postoperative followup. The antibody is elevated during the first four to six postoperative weeks, then decreases during the subsequent 12 to 18 months. In patients with a recurrence within two years of surgery, the antibody production remains at levels similar to that observed preoperatively (12).

Preoperative albendazole therapy, a radical surgical resection of the disease, including a chest wall resection if necessary, appropriate protection of the thoracotomy wound and of the pleural cavity from spilling should the cyst rupture during surgery, and additional postoperative albendazole therapy (three to six cycles) is the treatment of choice for chest wall hydatidosis. The preoperative albendazole reduces the risk of secondary hydatidosis should the cyst rupture during the operation. It should be started at least four days before surgery $(6,12)$. Özdemir et al (3) also reported good results of surgical resection in six patients with chest wall hydatid cysts, with follow-up of 14 to 36 months. An alternative treatment is a percutaneous puncture of the cyst, aspiration of most of the cyst fluid, injection of a protoscolicidal agent, and re-aspiration of the cyst fluid at least 15 min later. Despite some reports of good preliminary results by Filice et al (13) and Gargouri et al (14), the efficacy and potential risks of this method have not yet been fully evaluated. It may be considered for inoperable cases, or for patients who refuse surgery (6). 


\section{CONCLUSIONS}

A cystic mass located on the chest wall may represent a hydatid cyst. The characteristics consistent with this diagnosis include a well-circumscribed mass with a CT density close to that of water. When this diagnosis is likely, further manipulation of the cyst should be avoided to minimize the risk of rupture, and the patient should be referred for a surgical resection of the cyst.

\section{REFERENCES}

1. Aletras O, Symbas P. Hydatid disease of the lung. In: Shields TW, LoCicero J, Ponn RB eds. General Thoracic Surgery, 5th edn. Philadelphia: Lippincott Williams \& Willkins, 2000:1113-22.

2. Oguzkaya F, Akcali Y, Kahraman C, Emirogullari N, Bilgin M, Sahin A. Unusually located hydatid cysts: Intrathoracic but extrapulmonary. Ann Thorac Surg 1997;64:334-7.

3. Özdemir N, Akal M, Kutlay H, Yavuzer S. Chest wall echinococcosis. Chest 1994;105:1277-9.

4. Scott SM, Takaro T. Thoracic infections caused by actinomycetes, fungi, opportunistic organisms and echinococcus. In: Baue AE, Geha AS, Hammond GL, Laks H, Naunheim KS, eds. Glenn's Thoracic and Cardiovascular Surgery, 5th edn. Connecticut: Appleton \& Lange, 1991:261-87.
5. D'Alessandro A, Ramirez LE, Chapadeiro E, Lopes ER, de Mesquita PM. Second reported case of human infection by Echinococcus oligarthrus. Am J Trop Med Hyg 1995;52:29-33.

6. A WHO Informal Working Group on Echinococcosis. Guidelines for the treatment of cystic and alveolar echinococcosis in humans. WHO Bull 1996;74:231-42.

7. Porta R, Bravo-Bravo L, Aroca Conzales MJ, Aliz-Treuba A, Serrano Munoz F. Tumor and pseudotumors of the chest wall. Scand J Cardiothorac Surg 1985;19:97-103.

8. Karaoglanoglou N, Gorguner M, Eroglu A. Hydatid disease of the rib. Ann Thorac Surg 2001;71:372-3.

9. Alvarez Sala R, Gomez de Terreros FJ, Caballero P. Echinococcus cyst as a cause of chest wall tumor. Ann Thorac Surg 1987;43:689-90.

10. Redington AE, Russell SG, Ladhani S, Tungekar MF, Rees PJ. Pulmonary echinococcosis with chest wall involvement in a patient with no apparent risks. J Infect 2001;42:285-8.

11. Beggs I. The radiology of hydatid disease. Am J Roentgenol 1985;145:639-48.

12. Ramos G, Orduña A, García-Yuste M. Hydatid disease of the lung: Diagnosis and treatment. World J Surg 2001;25:46-57.

13. Filice D, Pirola F, Brunetti E, Dughetti S, Strosselli M, Foglieni CS. A new therapeutic approach for hydatid liver cysts. Aspiration and alcohol injection under sonographic guidance. Gastroenterology 1990;98:1366-8.

14. Gargouri M, Ben Amor N, Ben Chehida F, et al. Percutaneous treatment of hydatid cysts (echinococcus granulosus). Cardiovasc Intervent Radiol 1990;13:163-73. 


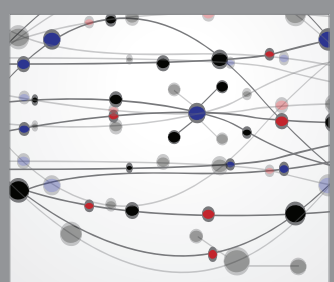

The Scientific World Journal
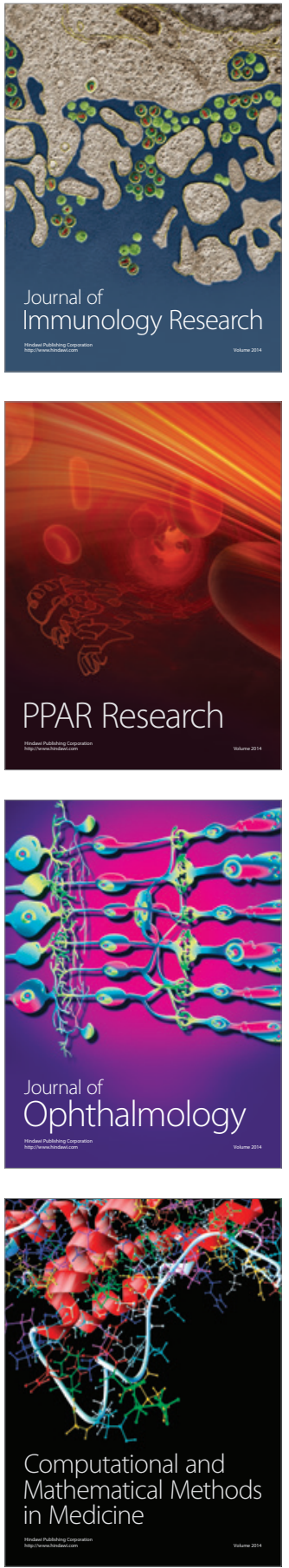

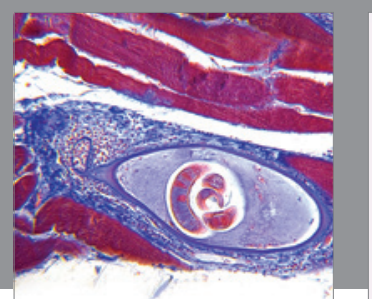

Gastroenterology Research and Practice

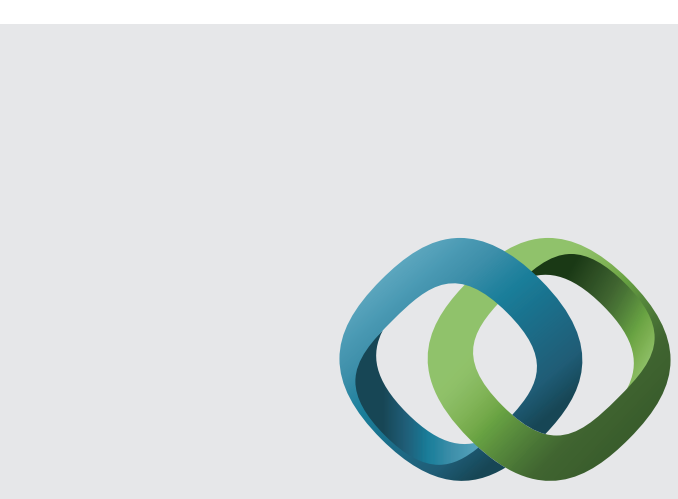

\section{Hindawi}

Submit your manuscripts at

http://www.hindawi.com
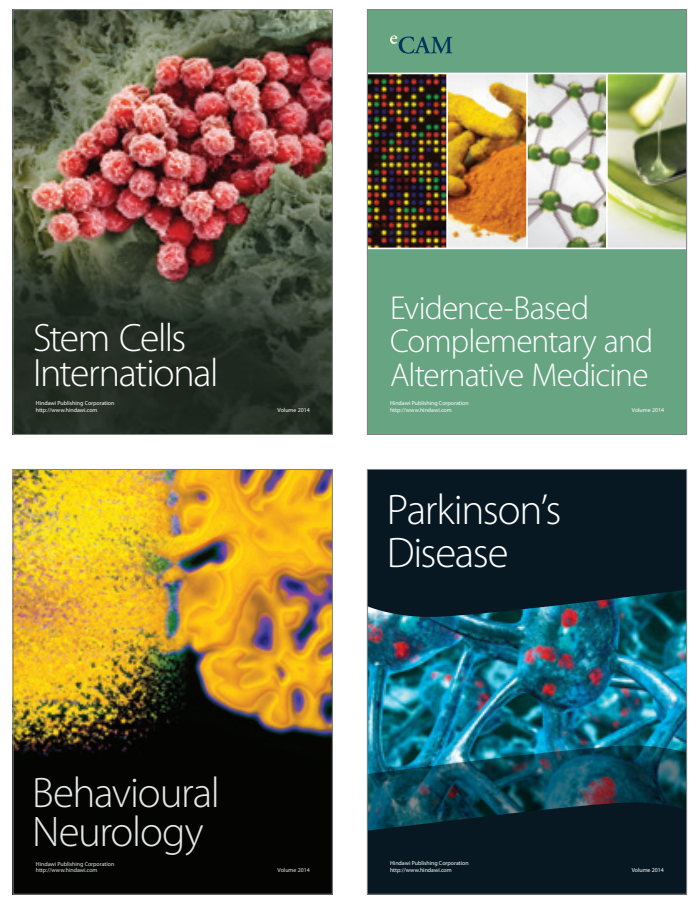
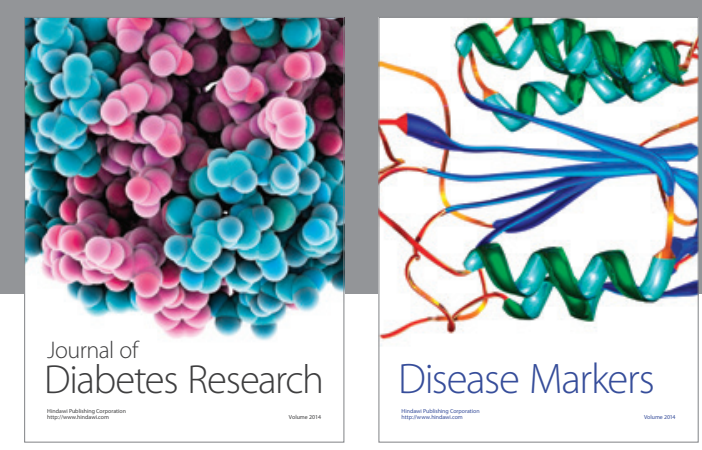

Disease Markers
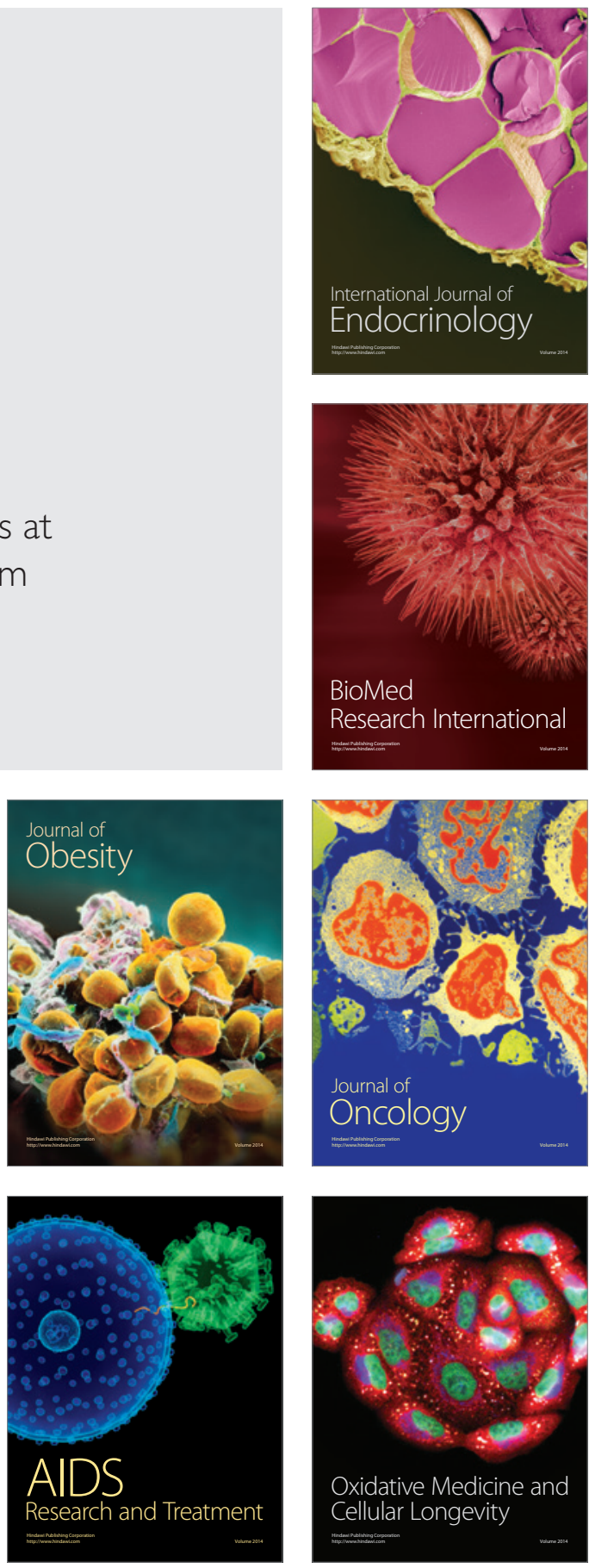